\title{
A bioarchaeology of climate and environmental change
}

By: Gwen Robbins Schug

Robbins Schug, G. (2020). A bioarchaeology of climate and environmental change. In G. Robbins Schug (Ed.), The Routledge Handbook of the Bioarchaeology of Climate and Environmental Change (pp. 1-16). Abingdon: Routledge.

This is an Accepted Manuscript of a book chapter published by Routledge in The Routledge Handbook of the Bioarchaeology of Climate and Environmental Change on 28 October 2020, available online: http://www.routledge.com/9781138492486.

****() 2021 Gwen Robbins Schug. Reprinted with permission. No further reproduction is authorized without written permission from Taylor \& Francis/Routledge. This version of the document is not the version of record. Figures and/or pictures may be missing from this format of the document. $* * *$

\begin{abstract}
:
Climate change is already having an impact on global public health, human security (including food and water security), and migration flows (IPCC, 2014). Governments and nongovernmental organizations are considering potential future impacts and creating plans for managing natural disasters, global warming, and associated environmental changes (DoD, 2015; EPA 2016a; b; c; d). The ability to understand global warming and predict and plan for the future relies on historical sciences. Paleoclimate science uses proxies to infer climatic and environmental fluctuations in the past, examining correlations among $\mathrm{CO}_{2}$ levels, mean global surface temperatures, ice coverage, sea-level rise, and paleoecology to develop models for prediction (Bender, 2013). Historical social sciences, including anthropology and archaeology, are also uniquely situated to contribute to these conversations based on our examinations of past human perceptions of and responses to climate and environmental change. For many decades, archaeologists and bioarchaeologists - who study human remains as a source of archaeological evidence- have been conducting scientific research on human-environmental interactions in the past and studying phenomena that will be highly valuable for contemporary planning and policymaking. Our scholarship addresses the socio-cultural-political dimensions of climate change over the last 12,000 years. Our data allow for nuanced interpretations of short-term strategies and long-term trajectories of human responses to environmental change.
\end{abstract}

Keywords: climate change | bioarchaeology | environmental change | human response | sustainability

\section{Chapter:}

Climate change is already having an impact on global public health, human security (including food and water security), and migration flows (IPCC, 2014). Governments and nongovernmental organizations are considering potential future impacts and creating plans for managing natural disasters, global warming, and associated environmental changes (DoD, 2015; 
EPA 2016a; b; c; d). The ability to understand global warming and predict and plan for the future relies on historical sciences. Paleoclimate science uses proxies to infer climatic and environmental fluctuations in the past, examining correlations among $\mathrm{CO}_{2}$ levels, mean global surface temperatures, ice coverage, sea-level rise, and paleoecology to develop models for prediction (Bender, 2013). Historical social sciences, including anthropology and archaeology, are also uniquely situated to contribute to these conversations based on our examinations of past human perceptions of and responses to climate and environmental change. For many decades, archaeologists and bioarchaeologists - who study human remains as a source of archaeological evidence - have been conducting scientific research on human-environmental interactions in the past and studying phenomena that will be highly valuable for contemporary planning and policymaking. Our scholarship addresses the socio-cultural-political dimensions of climate change over the last 12,000 years. Our data allow for nuanced interpretations of short-term strategies and long-term trajectories of human responses to environmental change.

The 27 chapters in this volume demonstrate there are no grand narratives in the arc of human history; however, these chapters do demonstrate a historical perspective on four major challenges facing contemporary human communities. Anthropogenic climate and environmental changes are occurring at a scale and a magnitude unprecedented in human history and they are already a significant threat to health and well- being. However, it is critical we recognize humans are biological organisms, enmeshed within an ecological system and completely interdependent on other species across the Kingdoms of life. Global warming is accompanied by the sixth mass extinction, which threatens the maintenance of life on Earth. We are also in the midst of an epidemiological transition, where modernity has brought sedentism, poor diets, obesity, and a rise in morbidity due to degenerative conditions. Unfortunately, we are also facing powerful challenges from emerging and re-emerging infectious diseases as we increasingly disturb wild spaces, interact with other species in detrimental new ways, and have mis-used antibiotic therapies. Bioarchaeological research as it is presented in this volume addresses hypotheses about every one of these current challenges and provides a deep-time perspective on humanenvironmental relations that is critically relevant to planning for a warmer world.

Although this has been a major area of research in our discipline, particularly since the 1970s, anthropology has, unfortunately, been conspicuously absent at the human security, policy, planning, and management tables (see Robbins Schug et al., 2019, for discussion). This volume brings together a sampling of bioarchaeologists working on the biocultural effects of humanenvironmental interactions, framing their research within global sustainable development goals. Sustainable development - creating the capacity to meet the needs of future generations while remaining mindful of the needs of the current human population - is at the core of creating a strategy for coping with global climate change and as such the United Nations (UN) has defined 17 major goals for global sustainable development as part of their policy agenda (Figure 1.1 ). These goals - outlined in the 2030 Agenda for Sustainable Development (https://sustainabledevelopment.un.org/) - were adopted by all of the United Nations member states in 2015. Here they are being used to organize the bioarchaeological research presented in the following chapters with the goal of demonstrating bioarchaeology's relevance to issues of contemporary concern and potentially making this work accessible and useful to policymakers and people from other disciplines, as well as to students who are interested in pursuing these questions in their future research. 
Sustainable Development Goals
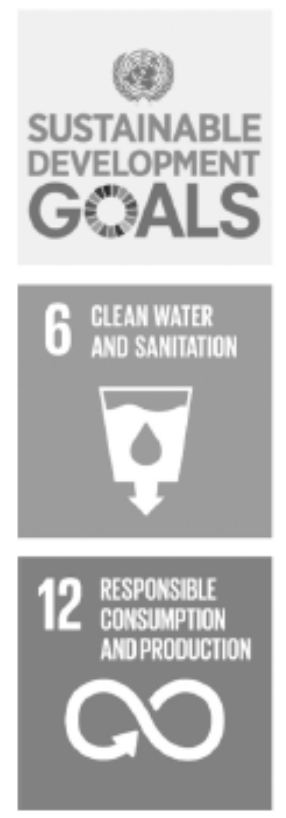
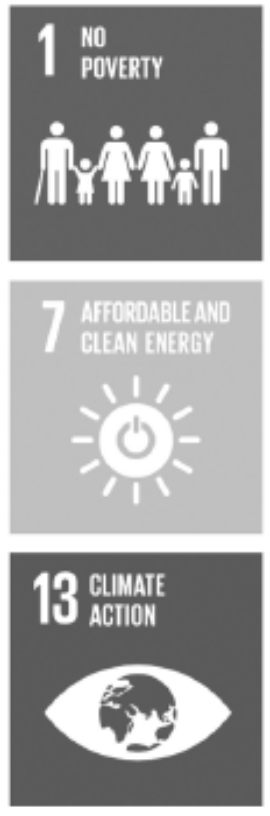
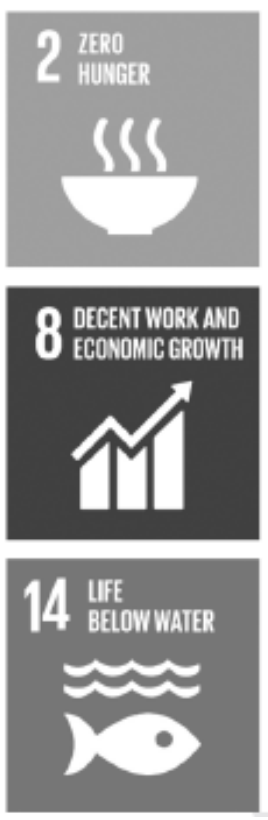
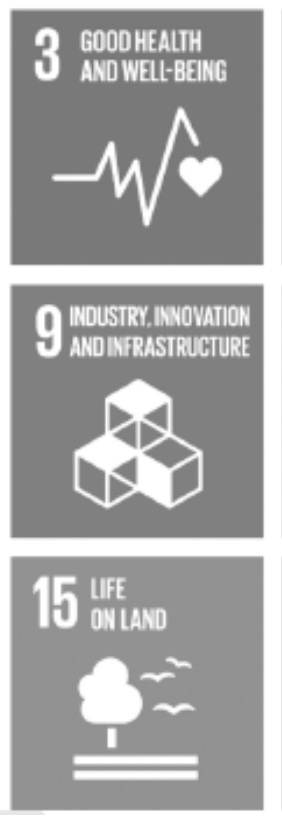
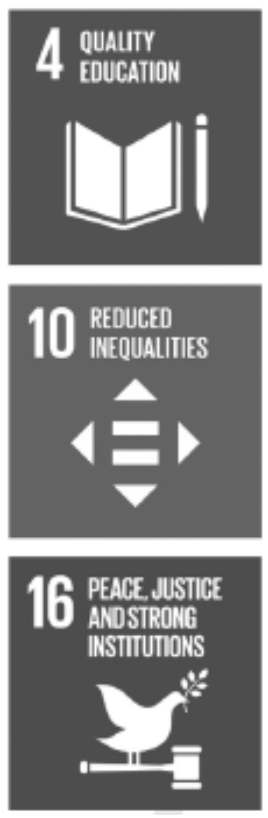
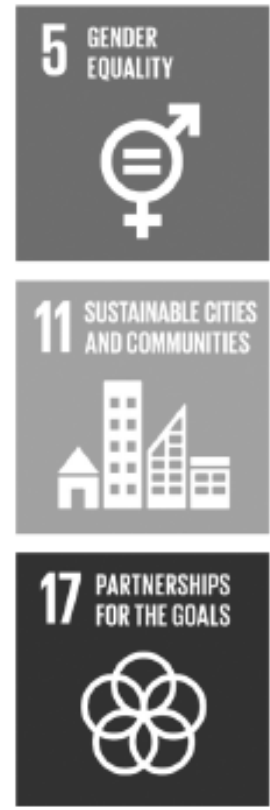

Figure 1.1. The UN's 17 Sustainable Development Goals (SDGs).

It is important to note from the outset that anthropological perspectives on sustainable development involve more than looking at global relations or making plans for coping with climate change. In anthropology, the concept of "sustainable development" includes a demand to also consider colonial histories and attitudes, territories of extraction and exploitation, and situated struggles over Indigenous sovereignty; anthropologists recognize the establishment of private property, disaster capitalism, and national borders as barriers for human mobility and adaptation; and we cannot escape from a consideration of the way history has defined global priorities for development, and the so-called "landscapes of power" (e.g., Powell, 2018 ). In archaeology and bioarchaeology, we take an approach that is both evolutionary and also deeply biocultural; we recognize that what, in other species, would be considered biological characteristics - what is food, who is a suitable mate, or who is related to us - are for humans deeply embedded in culture and history, to an extent that culture, history, and biology cannot be distinguished in human populations.

Bioarchaeologists have a lot to say about concepts and consequences inherent to the UN's sustainable development goals. Our research makes particularly important contributions to understanding human-environmental relations from a deep-time, cross-cultural perspective as we have defined a suite of diverse challenges to human "health" in the face of climate and environmental changes over the past 12,000 years. As the reader will see in the following chapters, bioarchaeological research is already contributing important insights on human health in the context of climate and environmental change in the following areas: occupational health hazards, air quality, and infectious pathogen susceptibility in the face of climate and environmental changes. Our research demonstrates how pandemics move through communities in the absence of modern medicine: we have access to data about differential susceptibility, the effects on the body in different socio-cultural circumstances, and the long-term, evolutionary 
outcomes of catastrophic mortality. We specifically include the role of socioeconomic inequality in constraining responses to and shaping the effects of environmental "crisis." We see climate crisis and pandemics as a space for socio- cultural change in the past. Our work addresses concepts of "vulnerability" particularly regarding environmental migration, culture contact, colonialism, violence, and "civilizational collapse." In our field, we have re-defined resilience by examining its relationship to diversity, flexibility, adaptability, and also the suffering that often accompanies survival through difficult circumstances. Our research considers the bodily impacts of life in diverse landscapes, entanglement with other species, health impacts of dietary change, famine, and other forms of resource stress. In other words, we already have insights on the UN's sustainable development goals and how these ideas have run like threads through human history.

The UN's 17 goals for sustainable development (Figure 1.1) represent a framework for planning for global climate change but they also represent an avenue for thinking about climate and environmental change in the past, for creating a bioarchaeology of human-environmental interactions and climate change that will have far-reaching impacts within and beyond academia. Specifically, chapters in this volume address the following sustainable development goals: good health and well- being (goal 3); socioeconomic and gender equality (goals 5 and 10), including the effects of poverty and hunger (goals 1 and 2); peace, justice and strong institutions (goal 16); and life on land (goal 15). The chapters have been arranged within sections entitled accordingly.

As the reader will find in the detailed descriptions below, almost every chapter in this volume addresses the goal of good health and well- being for women, infants and children and for communities facing climate and environmental change; however, this UN development goal is most strongly focused in the first section of this book, which explicitly examines maternal-infant mortality, infectious disease risk (particularly tuberculosis, malaria, and neglected tropical diseases), respiratory disease and other occupational health hazards. Good health and well-being cannot be separated from goals related to socioeconomic and gender equality, poverty, and hunger and these topics form the basis for the second section of this volume. The third section of this volume is deeply concerned with goal 16 (peace, justice, and strong institutions) as well as "life on land" (goal 15), which concerns our ability to live sustainably and in healthy relationships with other species on this planet. Each of these sections will outline the issues raised by these sustainable development goals, as framed by the UN, and will orient the reader to ways that bioarchaeological data address these issues.

\section{Goal 3: Good health and well- being}

Half of the human population alive today does not have access to adequate medical and health services. Maternal, infant, and child mortality is still a major challenge for life expectancy rates around the world. Air pollution, inadequate food and water sanitation, and other challenges of living in modern urban communities lead to occupational and mental health risks. Emerging and re-emerging infectious diseases - particularly tuberculosis, malaria, neglected tropical diseases, and insect-borne diseases - all represent major challenges for a warming world with increasing frequency and severity of natural disasters combined with over-population, over-crowding, millions living in impoverished conditions, and increasing antibiotic resistance. Many diseases that we thought to be a thing of the past are re- emerging as potent problems. Environmental degradation, capitalism, and global poverty bring us into contact with environments and other 
animals in ways that promote emerging infections. These issues are tackled in section one of this volume.

In Chapter 2 , Charlotte Roberts presents an overview of the concept of the "epidemiological transition" and argues that these should be referred to as "phases" because the word "transition" suggests a progressive order that is not appropriate in all contexts. Roberts defines our current condition, the "third epidemiological phase," as a period when morbidity and mortality are increasingly due to emerging infections, re-emerging infectious diseases, and antibiotic resistance. In the context of over- population and rising social inequality, climate and environmental change play an increasingly strong role in shaping this phenomenon, with global warming, natural disasters, deforestation, and other human- caused environmental changes presenting the biggest challenges to human health in the coming century-exposing human populations to new zoonotic diseases, altering patterns of disease transmission, exacerbating conditions that lead to antibiotic resistance, increasing pollution, and exposure to contaminated food and water. Roberts emphasizes the value of paleopathology as a tool for understanding human- pathogen co-evolution, epidemiological phases, and biocultural aspects of health in the face of changing environments in the past. She uses research on maxillary sinusitis in the past to illustrate how a historical perspective is useful for developing a fuller understanding of contemporary public health challenges. Finally, she provides some examples of how paleopathologists can bring our work into non- academic contexts to educate the public and members of the Global Health and Development community.

In Chapter 3 , Molly K. Zuckerman and Ashley C. Dafoe provide an overview of health and disease in the context of climate and environmental change over the past 10,000 years, describing bioarchaeological insights on these issues from the published literature spanning the past decade. Some work has been done on infectious diseases but for the limited number of studies conducted thus far, the primary impacts of climate and environmental change have been in the areas of interpersonal violence and subsistence transitions - food shortages and famines, dietary change and insufficiency that has led to signs of developmental disturbance and declines in adult stature, undernutrition and micronutrient deficiencies, rising infant mortality and measures of fertility — which have had particularly large effects on adult women, infants, and children in past populations. Highlighting published case studies from several bioarchaeologists, some of whom are also contributors to this volume-Elizabeth Berger, Sharon DeWitte, Ryan Harrod, Britney Kyle, Kelly Knudson, Deb Martin, Laurie Reitsema, Gwen Robbins Schug, Chris Stojanowski, and Hui Wang-Zuckerman and Dafoe convincingly argue that a useful theoretical framework for turning these case studies into a comprehensive but nuanced understanding of past patterns might be found in a model known as risk pathway thinking, which organizes the effects of climate change into direct, indirect, and tertiary impacts but maintains recognition of how political economy shapes vulnerability.

Chapters 4 through 8 take us through examples of periods in the human past where climatic and environmental changes likely contributed to changing patterns in human health and disease. These chapters consider the record of climate and environmental changes, the skeletal evidence for health, biocultural stress, and disease, and the possibility that there are important interactions between human health and the environment that are more than just coincidence. "Health" is difficult to address using human skeletal material and the term is here used to refer to a variety of 
traces on the human skeleton that mark periods where (1) homeostasis was disrupted to a degree significant enough to impact bones and teeth, (2) when inflammation and infection left generalized marks on the bones, or (3) specific micronutrient deficiencies and diseases can be identified by pathognomic signs on bones or teeth. It is important to recognize that, typically, signs of "stress" or pathophysiological disruption will be found in "healthy" populations; in other words, it is normal to have dental caries, degenerative joint disease, and even mild inflammation or infection in what we would otherwise consider a "healthy" human population (Klaus, 2014). Furthermore, as many chapters in this volume describe, sometimes "healthy" individuals have more signs of "stress" in the skeleton because they survive these stressful events; whereas "unhealthy" individuals, who are more frail, will express fewer signs of "stress" in the skeleton because they died before the skeleton was impacted (DeWitte and Stojanowski, 2015; Reitsema and McIlvaine, 2014; Temple and Goodman, 2014; Wood et al., 1992). If we were to defi ne health as "complete physical, mental, and social well- being" then the health of past populations cannot fully be assessed from human skeletal remains. Rather, these chapters explore the presence and prevalence of micronutrient deficiencies, signs of malnutrition, disruptions to growth and development as expressed in bones and teeth, and specific infectious diseases to create a nuanced view of how certain dimensions of human health are affected by climate and environmental changes but in recognition that, while the human skeleton is the most direct source of evidence on these questions, these data have their limits and they cannot tell the entire story.

Several of these chapters (4 through 7) are focused on climate- induced resource stress in four arid regions of the world - the Atacama Desert, the steppes and desert biomes of the Hexi Corridor in Northwest China, Medieval Iceland, and the Nile Valley in Egypt. These chapters consider human communities living in ecosystems that are often considered marginal environments for human habitation but, importantly, the authors focus on how human biocultural adaptations make these landscapes habitable, the character of resilience, and how human health impacts are part of the phenomenon of resilience, particularly for women, infants, and children. It is difficult to make predictions about how the arid regions of the globe will be affected by climate change and what specific environmental changes will result; climate feedbacks involving rainfall, temperature, $\mathrm{CO}_{2}$, and ecosystem effects are complicated but there is a consensus that arid and semi-arid regions will be among the most responsive ecosystems to climate change (see, for example, chapters by Snoddy and colleagues; Berger and Wang; Martin and Harrod; Pilloud and colleagues; Torres-Rouff; Juengst; Lieverse; Gregoricka; Schneider and colleagues; and Hrivnyak and Eng). This unpredictability and the promise of substantial impacts mean that looking to the past is a particularly important tool for makeing predictions about how climate and culture change can be inter-related, how "local biologies" might be impacted by the specific challenges of living in different global regions, and the relative long- term success of different short-term strategies employed by human populations living in these changing environments.

In Chapter 4, Anne Marie E. Snoddy, Charlotte L. King, and colleagues investigate human biocultural adaptations to resource stress and environmental instability in human populations that occupied that Atacama Desert from 3500 to 1500 years ago. This hyper-arid region represents a challenge for human occupation because of frequent extreme weather events and unpredictable food resource availability - for both terrestrial and marine foods. These authors set up a context for human habitation using paleoenvironmental reconstructions that include evidence for a 
variety of challenges, the most salient being an increasing frequency of El Niño/Southern Oscillation (ENSO) events in what was already a marginal environment. The authors hypothesized that this increase in ENSO events may have contributed to "micro-famines," dietary changes, and, ultimately, to impacts on human health across the Archaic to Formative Period transition. Their bioarchaeological analysis - combining isotopic evidence of changing dietary strategy and paleopathological evidence of nutritional sufficiency — of 187 skeletal, mummified, and partially mummified remains demonstrates that ENSO events affected fisheries and human food choices in times of cyclical or periodic resource scarcity. Although adaptive diversity - reliance on a variety of wild food resources including marine mammal organs and kelp - had once buffered these populations from nutritional insufficiencies, including scurvy (vitamin $\mathrm{C}$ deficiency), human responses to environmental change brought resilience and survival but with serious consequences for human health.

In Chapter 5, Elizabeth Berger and Hui Wang consider adaptive systems, subsistence transition, and biocultural stress in human populations living in the steppe and desert biomes of the Hexi Corridor, Northwest China, during the 4.2 ka Rapid Climate Change Event. In this case, bioarchaeological analysis demonstrates that despite substantial paleoclimate and archaeological evidence for climatic and environmental changes spanning Asia for the duration of this event, the people of this region in Bronze Age China did not suffer from resource shortages and did not adopt significant changes to their diets. The mixed agro-pastoral subsistence system provided the buffer of adaptive diversity that was missing in the case of the Atacama Desert communities just described, who had the additional burden of unpredictable ENSO climatic events on top of the already marginal environmental system. Rather than a resilience characterized by survival but with negative health impacts, resilience in the Hexi Corridor was associated with improvements in some measures of population health and well-being, such as taller stature and higher rates of survival in the face of minor physiological insults. This case study provides an important example of how small- scale societies, unfettered by significant social inequality and with relative freedom of mobility to employ a mixed agro-pastoral subsistence, can develop successful strategies for coping with climate change events that had much more significant and negative impact in the complex societies of Mesopotamia, Egypt, and the Indus Valley, or even in small village communities of central India.

Chapter 6 considers a small-scale society in a very different kind of arid landscape, with a consideration of human groups that lived in small farmsteads of Viking Iceland from the 10th to the 11 th century AD. When Medieval Europeans originally colonized the island, the climate was cold and the environment was relatively marginal but resilience was made possible through a suite of biocultural adaptations that largely buffered the human and livestock populations from low temperatures and difficult conditions. However, similar to the situation in the Atacama region, periodic short- term climatic fluctuations - in this case, caused by volcanic eruptionsare described in written annals and these were blamed for crop failure, famine, and social strife. In an analysis of human skeletons from two contemporaneous cemeteries, Guoný Zoëga and Kimmarie A. Murphy examined traces of stress in the skeleton - signs of developmental perturbation (stature estimation and linear enamel hypoplasia), nutritional disruption (porotic hyperostosis and cribra orbitalia), periosteal reactions (new bone formation, sinusitis, lower respiratory infection, and infectious disease), trauma, and degenerative joint disease. They found that infancy and childhood were precarious times for the early inhabitants of Iceland, with high 
infant mortality in the first two years, evidence for periodic nutritional insufficiency, growth disturbance in the dental enamel, and short stature. In Viking Age Iceland, the human population faced environmental precarity, periodic catastrophic events, and rigid social inequality with resilience but not without health impacts, particularly for the youngest members of the community.

Chapter 7 turns to the impact of aridification on the risk of respiratory disease in the Middle Nile Valley. Anna M. Davies- Barrett and colleagues remind us that particulate air pollution is already a serious health concern (directly responsible for more than 4 million deaths per year today) and it is sure to be exacerbated by climate change, rising socio economic inequality, poor living and working conditions, and socio- sanitation issues. Inflammation of the sinuses and upper respiratory tract caused by poor air quality is a serious health challenge in itself but it also predisposes people to infectious diseases and respiratory illness is a contributing factor to cardiovascular disease and cancer. In this chapter, the authors examine the evidence for the presence and prevalence of chronic maxillary sinusitis in skeletons from the Middle Nile Valley spanning the latter half of the Holocene, when socio- cultural changes - urbanization, increasing culture contact, subsistence transition, and increasing industrialization - coincided with environmental changes - desertification and aridification - and may have made people more susceptible to changes in air quality, upper respiratory disease, and respiratory infection. The data demonstrate a significant rise in maxillary sinusitis with climate change, greater reliance on agriculture, higher population density, settled village and urban life, mud-brick housing, and greater overall disease burden. The prevalence of sinusitis also significantly increased with industrialization, socio economic inequality, high population density, poor ventilation, and poor sanitation conditions of the Medieval period. Upper respiratory diseases will become of increasing concern as arid lands expand in the 21 st century, greater numbers of people move to urban areas, and industrialization continues apace.

Chapter 8 considers another marginal environment with a very different set of concerns. Chryssa Bourbou examines the health impacts of life in marshy landscapes, where warm temperatures and periodic flooding can lead to resource scarcity and infectious disease. Malaria was a significant challenge for Greco-Roman society and writers throughout the Roman Empire associated the disease with spiritual and magical causes on the one hand but also with a recognition of an environmental aspect on the other. Notions of summer as a pestilential time, marshes as breeding grounds for "minute animals" that could spread disease, and a particular risk for women and children abound in the writing of that time. Bourbou considers paleoenvironmental, archaeological, and isotopic evidence from human skeletons to reconstruct anthropogenic, environmental, and biological factors that put human populations at risk of malaria at the margins of the Roman Empire. She then examines indirect evidence for the presence of malaria and metabolic disturbances in non- adult skeletons from Roman Switzerland. The disease is not directly attested by the remains but bioarchaeological data demonstrate high infant mortality and infantile scurvy, providing additional support for the conclusion that reproductive- aged women, infants, and children tend to show the greatest burden of biocultural stressors in marginal environments and the context of environmental change.

Goals 1, 2, 5, and 10: Socioeconomic and gender equality, no poverty or hunger 
Climate change impacts human communities differently based on different historical trajectories and social environments. Chapters 9 through 14 consider the impact of social conditions in the past - inequality, urbanism, migration, culture contact, and new economic and political forms in the modern era, such as the invention of private property or the invention of "mental health" care-on "local biologies," human health, and well-being. By 2030 , more the $66 \%$ of the human population will live in cities and these overcrowded environments are increasingly structured by socio economic inequality (www.un.org/development/desa/en/news/sustainable/globalsustainable-development-report-2019.html). Although we might imagine that these environments are ripe for pandemics to spread, and undeniably they can be, there is also substantial biocultural variation among urban communities worldwide. Intersectionality as a theoretical framework reminds us also to consider a variety of axes of identity beyond the level of "urban," "poor," or "immigrant" communities when we think about social determinants of health (Crenshaw, 1990; Schultz and Northridge, 2004). Although health can be constrained in important ways by unequal social positioning, migration and social complexity can also open spaces for human agency, expanding socio economic or political opportunities, changing dynamics in social relations, and socio-cultural change more broadly, particularly in the face of climate changes.

In Chapter 9, Kenneth C. Nystrom and Gwen Robbins Schug consider how socioeconomic inequality broadly shapes health outcomes in the face of climate and environmental change. This chapter uses an analytical framework developed by the Intergovernmental Panel on Climate Change (IPCC) for thinking about how climate and environmental changes have impacted and will impact human communities - from the direct impacts of extreme weather events to ecosystem-mediated impacts, and impacts mediated through human institutions.

Bioarchaeologists can contribute to planning and policy discourse about direct impacts from climate change like drought and famine, eco-system-mediated impacts on infectious disease prevalence, and socially or institutionally mediated impacts of occupational and mental health hazards, population displacement, conflict and inter-personal violence, and nutritional insufficiency. But bioarchaeology has more to off er than just a view of the longue durée of health in the face of climate and environmental changes in the human past. Although that is an important perspective in and of itself - and climate science is fundamentally a historical science-bioarchaeology's most profound contribution to contemporary climate and environmental change research will be the demonstration of how to powerfully combine evolutionary, biocultural, political economy, critical medical anthropology, and other critical social theoretical frameworks to create a deeply contextualized view of contemporary anthropogenic climate change and to provide a nuanced view of human agency, resilience, and suffering across millennia of human-environmental interaction.

Chapter 10 provides a critical historical bioarchaeology framework for understanding emerging and re-emerging infections in urban populations facing climate perturbation. Sharon N. DeWitte considers how widening social disparities, population growth, and the Medieval Climate Anomaly affected the epidemiology of the Black Death and the disease's long-term effect on the city of London. Before the emergence of the Black Death, the Medieval Warm Period had brought a warm, stable climate and dramatic population growth to 14th-century England. Although environmental conditions for agricultural production were favorable, periodic food shortages and famines, rising social inequality, and economic precarity meant that the population as a whole was not necessarily well-fed. By the end of the 13th century, climatic instability 
brought increasingly frequent famines and infectious diseases that contributed to a rising death toll for humans and livestock. Growing structural inequality, with 40\% of the population of England considered "poor," and socio-sanitation problems associated with rapid urbanization led to conditions favorable for the spread of infectious diseases. Bioarchaeological analysis reveals that survivorship was already declining in 13th- century London, along with stature. Social, economic, and biocultural conditions worsened in the century leading up to the Black Death and bioarchaeology has demonstrated the mortality from plague was highest among people who already demonstrated evidence of skeletal stress from nutritional insufficiency and other infections. The Black Death emerged in the urban environment in the context of climate change and unequal social conditions to have the greatest impact on the most vulnerable segments of an overcrowded society.

Britney Kyle and Laurie Reitsema (Chapter 11) consider skeletal markers of stress and "health" at the intersection of incipient urbanism, culture contact, social inequality, and several axes of identity in the Greek colony of Himera, Sicily. Kyle and Reitsema are primarily considered with examining how the concepts of "ethnicity" and "marginalization" may emerge from the bioarchaeological record of a port city, how these intersect with skeletal stress markers, and how these traces on the skeleton might inform us about health patterning as it is shaped by ethnic marginalization and poverty today. Although in the past archaeologists often assumed that burial position, grave styles, and grave goods were straightforward markers of social status and identity, for decades now there has been a recognition that identity is complex; mortuary behavior is a symbolic performance by the living, rather than a portrait of the dead; and sociopolitical conditions, ideological systems, and many other factors play into the treatment of the dead. At Himera, there was a complex relationship among burial style, grave goods, age- atdeath, and skeletal stress markers that suggests the style of the graves - tile capped or simple pit burial - symbolized social status and a certain amount of biocultural buffering against the effects of stress. Social positioning affected health but this effect was not structured by skeletal sex or the number of grave goods. In the Mediterranean, environmental determinism and casual observations of social inequality - or "access to resources"- has been used to assign blame for the "success or failure" of past societies. A bioarchaeological, deeply contextualized analysis of burials, treatment of the body, and paleopathology is key to creating a more nuanced view of social structure and agency as they shape health outcomes.

Cyprus too has a long history of culture contact, exchange, and population movement. In Chapter 12 , Anna J. Osterholtz suggests that unlike a colonial framework - in which one population imposes social structure and cultural identity norms on another-health, behavior, and interpersonal violence patterning in Bronze Age Cyprus reflect a changing social environment and the opening of a Third Space phenomenon of culture contact. From a practice perspective, individuals who live in trading societies construct their identity in a fluid landscape of hybridization. Social relations in this Third Space are defined by the interactions among diverse cultural, behavioral, and biological elements. An analysis of skeletal material from Cyprus demonstrates traumatic injury and violent interactions occurred with relatively consistent frequency across the Bronze Age Transition. Skeletal stress markers too were consistent, suggesting that the increasing levels of culture contact and intermingling of people from diverse backgrounds did not generate social upheaval as has often been demonstrated in instances of settler colonialism. Rather, the diverse Cypriot social landscape was one of integration and the 
formation of new identities, with shared social, cultural, and biological features and shared health outcomes.

The late modern period of the 19th and 20th centuries has seen the emergence of new and dramatically different forms of climate and environmental change - unprecedented population growth; the beginning of anthropogenic global warming, vast habitat destruction, the sixth mass extinction, and new forms of environmental pollution beginning with the Industrial Revolution; the emergence of capitalism on a global scale, extreme socio economic disparity, private property, and disaster capitalism; the end of slavery and settler colonialism as they were practiced in the early modern era but new forms of social inequality, human trafficking, racism, world wars, and genocide; the emergence of scientific perspectives on human anatomy, biology, health, disease, and medical treatment; increasing connectivity, culture contact, communication, mass media, and the opening of a digital universe; among many other changes to the physical and social environments in which we live. Chapters 13 and 14 move our consideration of social environments beyond the realm of urbanism, culture contact, and colonialism-processes at work for more than five centuries - to a consideration of paleopathology in the context of fully modern challenges to human health.

Megan A. Perry and Emily Edwards use a case study from 19th-century Hisban, Jordan, to examine the potential health impacts of the imposition of a system of private property to accomplish economic, political, and social goals in the Ottoman Empire. Property ownership is a modern phenomenon that will increasingly impose significant challenges for human communities facing climate and environmental change in the coming century. For most of human history, populations had options to emigrate as one coping strategy for dealing with environmental change; contemporary human populations face new challenges to migration with property privatization, the imposition of national borders, and novel identities as "environmental refugees" whose social position in the global community brings a new set of risks and challenges to health. In Jordan, land rights were historically negotiated among tribal communities until the mid-1800s, when the Ottoman Empire instituted Tanzimat reforms to reify political control and bolster the Empire's financial status. The system had a profound impact on the formerly nomadic Bedouin people, who were pushed into more marginal areas or who acquired land but were then effectively forced to settle on the landscape, transition to food production, and often ended up in debt. A consideration of bioarchaeological evidence of burial patterns and skeletal stress markers, deeply contextualized in the historical record and ethnographic records about tribal identity and culture, demonstrates significant health challenges for new mothers, infants, and children among 19th- and 20th-century Bedouin people compared to earlier skeletal populations and demonstrates the experience of resilience among different segments of the community. As we have seen in several other chapters, when health is affected by climate and environmental change, social position and marginality play a role in shaping outcomes and often it is women and children who bear the brunt of those impacts.

In Chapter 14 , Megan Miller, Gwen Robbins Schug, and colleagues describe a bioarchaeology of madness based on historical records and human remains from hospitals (ospedale) and insane asylums (maniocomio) from northeastern Italy (18th and 19th centuries). Human environments in the modern period have been profoundly altered by abstractions of global colonialism and capitalism, the medicalization of the human condition, and the rise of state-level interventions in 
health, including institutionalization. This chapter examines the embodiment of these forces using cranial remains from the manicomio at Sant'Anna Ospedale in Ferrara, Italy. Miller and colleagues take a bioarchaeological approach to irrationality in the Age of Empiricismdescribing the global and local socio- economic- political forces that led to corn becoming a staple crop in northeastern Italy, the rise of pellagrous mania and other forms of alienazione mentale, and how the development of modern medical perspectives, psychiatry, and mental institutions shaped the experiences of the pellagrosi. Osteobiographies in this chapter tell a story of pathophysiological processes related to marasmus, pellagra, and violent death. Through these portraits, this historical bioarchaeology vividly demonstrates the suffering that often characterizes modernity for poor and inconvenient people.

\section{Goal 16: Peace, justice, and strong institutions}

It is a commonly held view in the global development and policy planning world that climate change will lead to increased migration flows and that competition for limited resources will result in increased levels of violence (see discussion in Robbins Schug et al., 2019). Violence is deeply connected to strong institutions with a mission to promote peace and justice. When social institutions are built instead on a foundation of social inequality, injustice, and deprivation this makes violent responses to instability, including climate and environmental change, more likely. The chapters in this section demonstrate many circumstances where inter-personal and community-based violence were not substantially correlated with periods of climatic and environmental disruption. In a few cases, violent interactions increased in times of climate uncertainty but the authors point out particular historical, socio-cultural, and ideological phenomena that promoted this behavior over the alternatives. These chapters provide perspectives on violence and social institutions that converge on a few simple ideas: interpersonal violence is in no way a "natural outcome" of climate and environmental change; violence is not necessarily abated by strong social institutions, particular forms of government, or tighter social control, phenomena that can also represent forms of violence; and there is no single meaning of nor a single trajectory for violent behavior in human history.

In Chapter 15, Rebecca Redfern takes the reader through the evidence for violent interactions in Europe, beginning in prehistory and ending with the Medieval period. The chapter starts with the premise that the effects of climate change cannot be distinguished from structural inequality and racism. Often it is socio-cultural constraints that have limited peaceful responses to climate change and violence is, therefore, more likely to emerge as a response in circumstances of social inequality and injustice. Socio economic inequality and interpersonal violence are first demonstrated in the Neolithic settlements of Austria and Germany, with early adoption of farming, sedentism, and commensurate increases in population size. Much of the work on the phenomenon of societal collapse in Late Bronze Age Mediterranean societies has also focused on the role of environmental crisis and famine. Finally, the Medieval Warm Period and the Little Ice Age had profound impacts on European history, society, economy, and health from the 11th to the 17th centuries $\mathrm{AD}$. Although the climate is only one among a large number of other variables implicated in episodes of past violence in Europe, and much additional work is needed to tease apart the complexities of the data, there does seem to be a role for environmental change in the case studies of violence presented here. 
Debra L. Martin and Ryan P. Harrod (Chapter 16) examine the impacts of climate and environmental uncertainty on inter- personal violence, specifically witch executions in the American Southwest. For the Indigenous communities known as the Ancestral Pueblo, environmental uncertainty was a consistent biocultural challenge, which these communities successfully met for centuries and which shaped so many aspects of culture, from ideological and cosmology systems to structural features like marriage patterns, architecture, and processes of governance. Martin and Harrod focus on the interface between a sense of disruption that arises during periods of environmental change and supernatural explanations for this chaos in historical and ethnographic records of sorcery. They use ethnohistoric, archival, oral, and archaeological evidence to evaluate the hypothesis that large assemblages of disarticulated human remains might be a result of witchcraft executions on the Colorado Plateau. While unpredictable weather patterns were once used as a basis for explaining the evidence for large-scale raiding, warfare, and cannibalism in this region, this chapter makes a strong case for an alternative model of increasing environmental uncertainty leading to increasingly frequent accusations of witchcraft and attempts to respond to these transgressions using ritual executions. The chapter ultimately demonstrates specifically how cross-cultural, ethnographic, and historical perspectives lead to a more nuanced understanding of human responses to environmental uncertainty.

In Chapter 17, Marin A. Pilloud, Al W. Schwitalla, and Kristen A. Broehl describe the effects of the Medieval Climatic Anomaly on Indigenous populations in central California. Although this region suffered similarly difficult climatic and environmental challenges from 800 to $1350 \mathrm{AD}$, their responses to these challenges were dramatically different from those of the Ancestral Pueblo communities represented in Chapter 16. The Medieval Warm Period led to welldocumented warmth and drier conditions in southern and central California and the Channel Islands. At that time, this region was also densely populated with hunter-forager communities with a strongly diverse set of social, cultural, and linguistic traditions. While researchers have documented increasing social complexity, biocultural stress markers and skeletal evidence for violent interactions in skeletal populations from Indigenous communities in southern California and the Channel Islands, central California's Indigenous communities show a plethora of diverse responses to environmental change and a high degree of regional variation in the level of biocultural stress and violent interactions. In some cases, environmental stress was associated with reductions in traumatic injuries and trophy taking; in other cases, there is evidence for increasing levels of interpersonal violence from sharp force or projectile trauma. Historical and sociocultural factors create these different responses to environmental changes within one region.

We return to the hyper- arid Atacama Desert region in Chapter 18 with Christina Torres-Rouff 's examination of human skeletal remains from the Late Intermediate Period, a time of climatic volatility and increasing aridity in an already marginal and arid environment. The Late Intermediate Period was also a time when the archaeological record demonstrates massive social reorganization, culture changes, and a shift to larger population sizes living in defensive settlements. Prior analyses of human remains from this time show clear evidence of reduced stature, non-specific stress, and nutritional deficiency. Despite all of this evidence for environmental, cultural, and social change and physical hardship for people living in this area at that time, there is no clear association with the prevalence of traumatic injuries. On a gross level, the prevalence of traumatic injury increases over time in the Late Intermediate Period; however, a more detailed analysis demonstrates this variation in the rates of injury is structured along 
several different axes including local geography and burial practices. Like many of the other authors in this volume, Torres-Rouff concludes that violence was experienced unevenly; it may have been a consequence of chaotic social and inter-personal relations rather than climate change; and, violence occurred within a milieu of social inequality, uneven access to resources, and increasingly difficult environmental circumstances.

One thing that has been repeatedly demonstrated by anthropologists and archaeologists in this volume and over decades of research is that human populations are highly variable over time and space because of different historical and socio-cultural trajectories. Because humans are fundamentally biocultural organisms - biology and culture are so deeply intertwined as to be inseparable - it is not a foregone conclusion that climate and environmental changes will result in violence and violence has different meanings cross- culturally and through time. In Chapter 19, Sara L. Juengst investigates 3000 years of traumatic injuries in the Titicaca Basin of Bolivia, which has fairly consistent rainfall and seasonality but a highly unique set of ecological, altitudinal, and terrain conditions for its low latitude. Paleoenvironmental reconstructions chart changes in lake levels over time, which have been particularly variable over the past 3500 years. These lake level fluctuations correspond to archaeological evidence for socio-cultural changes and may, therefore, have presented environmental challenges to the local human communities. Large-scale social changes - sedentism, subsistence transitions, and urbanization-present similarly important environmental challenges. Juengst informs us that violent injuries on human skeletons from the Andes are expected to result from a diverse array of different processes including corporal punishment against women and children, large-scale warfare, raiding, ritual sacrifice, and the manipulation of bodies after death. Violence was a socially acceptable practice and this is embodied by one-third of the individuals studied across this time-frame. The prevalence of injuries is higher during periods when lake levels were lower, or when other widely felt environmental changes took place (like the adoption of agriculture); however, low lake levels did not always correspond to increasing evidence for violence and it is a commensurate increase in social complexity, emerging hierarchy, and elite rivalry that seem to have been responsible for violent interactions.

Chapter 20 investigates the role of climate and environmental change in shaping patterns of violence in Jōmon society. Hisashi Nakao and colleagues trace the ecological and socio-cultural developments in the Japanese Archipelago over 12,000 years, demonstrating that interpersonal violence was never a substantial part of $\mathrm{J} \overline{0}$ mon social interactions and postulating specific cultural features - values focused on nurturance, migration, and other social mechanisms of conflict avoidance - may have promoted more peaceful responses to change over time. Jōmon people established a semi-sedentary hunting and foraging lifestyle in Japan throughout the Holocene and during that time generations of people witnessed climatic and environmental shifts, including the warm period known as the Holocene Climatic Optimum (9000-5000 BC) or cooling and drying trends (such as the $4.2 \mathrm{ka}$ event), all of which led to sea-level fluctuations and ecosystem turnover, and are associated with settlement size declines and, in some cases, settlement collapse. Archaeological evidence demonstrates substantial changes in material culture over this long time-span and bioarchaeological evidence suggests there might have been an increase in violent conflict throughout the Holocene but rates of injury remained relatively low and the incidence of traumatic injury was geographically dispersed. 


\section{Goal 15: Life on land}

The fifteenth goal, "Life on Land," refers to the goal of promoting healthy relationships with the natural environment and other species. The UN is focused on protecting and restoring terrestrial ecosystems, sustainably managing forests, understanding and combatting desertification, and halting environmental degradation and biodiversity loss. The chapters in this section seek to understand how past people made choices related to challenges of different landscapes, some of which might today be considered "sustainable"; sustainability is conceived not in a way that promotes a naturalistic fallacy or romanticizing of the past but, rather, in a way that combats narratives of past people as living in affluence rather than as making "good" choices. This section also considers challenges for human communities when "making a living" or trying to traverse particularly challenging — high altitude or hyper-arid-landscapes. Finally, this section concludes with a consideration of our entanglements with other animals and how data from different species must be contextualized before interpretation is undertaken. These chapters take different theoretical approaches, using ideas from historical sustainability or entanglement theory, but throughout this section there is a common thread of how the landscapes we live in influence, constrain, and provide unique opportunities for human communities facing climate and environmental change.

Mark James Hudson (Chapter 21) considers whether archaeologists and bioarchaeologists can identify long-term sustainability in prehistory using an example from the Jomon people of Japan. After opening with a cautionary statement about how anthropologists have often portrayed Japan as a bountiful paradise and affluence as an essential characteristic of Jōmon society, Hudson encourages bioarchaeologists instead to instead think about "biocultural adaptations" to environmental challenges through the lens of historical sustainability - to trace the development of sustainable lifestyles and practices as a series of choices and strategies employed by past people. The chapter examines how social complexity and intentional simplification were used as strategies for dealing with environmental catastrophes, epidemic diseases, and the slow, mosaic process of Neolithization in Japan.

Chapter 22 takes a different approach to traumatic injuries, framing these as a consequence of living in the mountainous terrain of the Mustang region of Nepal. High-altitude environments presented well-documented challenges for human habitation from the altitude, steep and uneven terrain, scarce resources, and extreme weather conditions. Despite these challenges, human communities have occupied this landscape for millennia. This area is particularly vulnerable to global warming and associated environmental changes; after summarizing some of the predicted impacts on human communities in this region, Jacqueline T. Eng and Mark Aldenderfer look to historical, ethnographic, archaeological, bioarchaeological, and clinical sources of evidence about human-environmental interactions over time to elucidate a suite of factors responsible for patterns of trauma in the human remains. Natural disasters, hazardous trails, raising large domesticated animals, falls, violent interpersonal encounters, and larger-scale organized violence can be invoked to explain skeletal injuries in this region. While the postcranial injuries largely appear to be explainable as the result of falls, evidence for cranial trauma is likely a result of competition for scarce resources but this chapter and the one by Juengst demonstrate a low prevalence overall of violent interactions, which demonstrates that despite living in what might 
be considered a marginal environment, high- altitude populations of the past were often at low risk of violent confrontations over scarce resources.

Angela R. Lieverse takes a different approach to activity, not as a source of acute trauma but as a type of chronic change to bone surfaces that can reflect habitual activities that form the everyday basis of human-environmental interactions. Lieverse considers skeletal evidence for changing behavioral and subsistence strategies across the mid-Holocene in the Cis-Baikal region of Siberia, a period that saw considerable environmental variability and a region deeply threatened by contemporary global warming. Lieverse draws a connection between osteoarthritis (degenerative joint disease) and changes to entheses (tendon or ligament attachment sites) to reconstruct specific movements conducted in the course of daily life for hunting and gathering people who lived in this steppe-forest biome in the warmer and wetter centuries after $6500 \mathrm{BP}$. Archaeological research has not resulted in a clear picture of how these communities may have altered their subsistence practices at this time but the bioarchaeological evidence shows that patterns of skeletal loading were significantly different over time in response to local ecologies, different social organization, and different strategies for coping with environmental changes.

Lesley A. Gregoricka (Chapter 24) investigates subsistence transition and increasing mobility as potential strategies for coping with the aridity and environmental changes that occurred in the Arabian Peninsula at the end of the Bronze Age. Using strontium and stable carbon isotope ratios from skeletal material of people interred in a monumental tomb in the UAE, she finds evidence for a shift in climate (regional aridification) and a striking uniformity in stable isotope values that suggests relative uniformity in diet and relatively low levels of mobility and migration at that time. Despite high levels of mobility in other West or South Asian human communities at that time, resilience on the Arabian Peninsula took the form of an attempt to maintain a consistent lifestyle and food habits in the face of a lot of regional social and environmental change. These data from the site of Shimal represented an important and unique opportunity to see climate, dietary, and mobility changes within a single community over the second and third millennia $\mathrm{BC}$, a perspective not provided by previous similar types of analyses of samples from the Arabian peninsula, which were from sites that were abandoned earlier or yielded skeletal remains too fragmentary to examine change over time.

Chapter 25 takes the reader to an Early Bronze Age urban center in the Lower Turkish Euphrates watershed of southeastern Anatolia. In this chapter, Adam W. Schneider and colleagues also use an isotopic approach on human skeletal material to address long-standing questions about the specific effect of climate change on human communities in this region, the pace of those changes, and how that corresponds to the strategies employed by human communities. The term "collapse" has often been employed to describe the reorganizatio of past urban civilizations faced with changing climate. This term is rightly debated in archaeology and bioarchaeology as authors from other disciplines (Jared Diamond, Steven Pinker, etc.) have loaded up the concept with a lot of baggage: judgment, inaccuracies, doomsday prophecies, and false claims, among other problematic usages. Because of these misconceptions proffered by popular books, skeptical anthropologists in decades past may have been a little too reluctant to imagine that climate could play a role in major population reorganizations; may have been extra reluctant to describe social and biocultural consequences of environmental change in some societies. More than offering a regional case study about the effect of the $4.2 \mathrm{ka}$ event on West Asian civilization, this chapter 
considers the evidence within this larger frame, weaving in the historical and particular factors that made some communities more susceptible to others. AMS dates and oxygen isotope signatures demonstrate solid evidence for climate change in the human remains. Furthermore, they found evidence that as political centralization broke down, dietary diversity began to increase. Although Titris Höyük was an important regional center in this region, changing climatic, environmental, social, political, economic, and cultural factors contributed to increasing levels of violent trauma and the eventual abandonment of the town at the beginning of the second millennium BC.

In Chapter 26 , Michelle Hrivnyak and Jacqueline T. Eng examine environmental dynamics and isotopic signatures in Inner Asian Steppe populations of northern China-Mongolia, Inner Mongolia, and Xinjiang. The goal of this chapter is to more explicitly consider arid and temperate environments as these two different settings are reflected in carbon and nitrogen isotope signatures. Using human remains from seven archaeological sites dated to the Late Bronze Age, Early Iron Age, and Iron Age, Hrivnyak and Eng measured stable carbon and nitrogen isotopes to estimate dietary strategies over time and across these different ecological zones, finding that diet, aridity, temperature, and ecological circumstances shaped patterns of variation.

Last but certainly not least, in Chapter 27, Judith Littleton and colleagues have made an important contribution examining human- animal entanglements in Remote Oceania. As John Donne (1572-1631) wrote in his Meditation XVII, "No man is an Iland, intire of itselfe; every man is a peece of the Continent, a part of the maine ...." As humans, we live in close commensal relationships with a large number of different species. In environmental archaeology, we use animal remains as proxies for human migration, diet, disease, physiological stress, or even just as a background measure of environmental values against which to judge human isotopic signatures. Littleton and colleagues caution that using other species as a proxy for humans is not so straightforward and one must consider how life history, physiological differences, and site formation processes may diff er across different species. These authors review isotopic and dental anthropology evidence in a multi- species approach to infer shifts in human- animal food-webs, domestic management strategies, and regional environmental changes in the Pacific Island context. Like the other chapters in this section, Chapter 27 demonstrates the power of putting humans on the landscape, considering sustainability and relationships with other species in the context of past climate and environmental change.

The United Nations has reached out to scholars and institutions of Higher Education with their Higher Education Sustainability Initiative (HESI) and they have asked us to engage with and contribute to these 17 goals by thinking about creative and innovative ways to address them in our research, asking us to integrate them into our curriculum, educate students about the goals and encourage them to conduct their own research along these avenues (https://sustainabledevelopment.un.org/sdinaction/hesi). This book has addressed a few of these areas but other sustainable development goals - clean water and sanitation (goal 6), decent work and economic growth (goal 8), sustainable cities and communities (goal 11), responsible consumption and production (goal 12), and life below the water (goal 14) - could potentially be addressed by future bioarchaeological research. Perhaps inspired by the authors in this volume, future generations of scholars may take up the goal of speaking more directly to these concerns 
as well. While the UN is very much focused on the future and enacting changes in directions they see as positive for our global community, these goals must be rooted in interdisciplinary scholarship and would be enriched by the participation of anthropologists (of all types), particularly as the global community considers what "sustainable development" means for Indigenous communities (e.g., the Asia Indigenous Peoples' Act) and vulnerable island populations (e.g., the Barbados Plan of Action) around the world. Anthropologists, and particularly bioarchaeologists who work on human- environmental interactions at the intersection of past, present, and future, have great potential to contribute to these discussions. This volume begins that conversation.

\section{References}

Bender, M.L. (2013). Paleoclimate (Vol. 8). Princeton : Princeton University Press.

Crenshaw, K . (1990). Mapping the margins: Intersectionality, identity politics, and violence against women of color. Stanford Law Review, 43, 1241.

DeWitte, S.N., \& Stojanowski, C.M. (2015). The osteological paradox 20 years later: Past perspectives, future directions. Journal of Archaeological Research, 23 (4), 397-450.

DoD. (2015). National security implications of climate-related risks and a changing climate. Department of Defense. Retrieved November 28, 2016, from www.defense.gov/Portals/1/Documents/pubs/150724-congressional-report-on-nationalimplications-of-climatechange.pdf

Donne, J. (1999). Meditation xvii. Devotions upon emergent occasions, 1624, 344-445.

EPA. (2016a). Climate change: Basic information. Environmental Protection Agency (EPA). Retrieved November 28, 2016, from www.epa.gov/climatechange/climate-changebasicinformation

EPA. (2016b). Climate impacts on ecosystems. Environmental Protection Agency (EPA) . Retrieved November 28, 2016, from www.epa.gov/climate-impacts/climate-impacts$\underline{\text { ecosystems }}$

EPA. (2016c). Climate impacts on agriculture and food supply. Environmental Protection Agency (EPA). Retrieved November 28, 2016, from www.epa.gov/climateimpacts/climateimpacts-agriculture-and-food-supply

EPA. (2016d). Climate impacts on water resources. Environmental Protection Agency (EPA) . Retrieved November 28, 2016, from www.epa.gov/climate-impacts/climateimpactswater-resources

IPCC (Intergovernmental Panel on Climate Change). (2014). Climate Change 2014: Mitigation of Climate Change. Contribution of Working Group III to the Fifth Assessment Report of the Intergovernmental Panel on Climate Change. Cambridge: Cambridge University Press.

Klaus, H.D. (2014). Frontiers in the bioarchaeology of stress and disease: Cross-disciplinary perspectives from pathophysiology, human biology, and epidemiology. American Journal of Physical Anthropology, 155(2), 294-308. 
Powell, D.E. (2018). Landscapes of Power: Politics of Energy in the Navajo Nation. Duke University Press.

Reitsema, L.J., \& McIlvaine, B.K. (2014). Reconciling "stress" and "health" in physical anthropology: What can bioarchaeologists learn from the other subdisciplines? American Journal of Physical Anthropology, 155 (2), 181-185 .

Robbins Schug, G., Parnell, E.K., \& Harrod, R.P. (2019). Changing the climate: Bioarchaeology responds to deterministic thinking about human-environmental interactions in the past. In J.E. Buikstra (Ed.), Bioarchaeologists Speak Out (pp. 133-159). Cham: Springer.

Schulz, A., \& Northridge, M.E. (2004). Social determinants of health: implications for environmental health promotion. Health Education \& Behavior, 31(4), 455-471.

Temple, D.H., \& Goodman, A.H. (2014). Bioarcheology has a "health" problem: Conceptualizing "stress" and "health" in bioarcheological research. American Journal of Physical Anthropology, 155 (2), 186-191.

Wood, J.W., Milner, G.R., Harpending, H.C., Weiss, K.M., Cohen, M.N., Eisenberg, L.E., ... Katzenberg, M.A. (1992). The osteological paradox: problems of inferring prehistoric health from skeletal samples [and comments and reply] . Current Anthropology, 33 (4), $343-370$. 